\title{
Bajo el agua de Fernanda Galindo
}

"Bajo el agua" fue el proyecto ganador de la IV Convocatoria del Fondo de Apoyo a la Producción de Sonora 2017, auspiciado por la Secretaría de Educación y Cultura y del Instituto Sonorense de Cultura del estado de Sonora y de la Secretaría de Cultura.

Escrito y dirigido por Fernanda Galindo y, producido bajo el sello de "Unoenlouno Films" la autora explora su historia personal en el devenir de sus historias. Abrimos ahora el baúl de los recuerdos para ofrecer una lectura abierta sobre el contenido de su trabajo. "Bajo el agua" fue publicado en la red social Vimeo. (https://vimeo. com/261950883), en noviembre de 2018. En este número, su autora aparece, además, como coautora de uno de los artículos publicados.

"Padre e hija" de Michael Dudok de Wit (2000), ofrece una versión de lo queda al descubierto cuando el agua deja de fluir en un lago, la ausencia de agua desenmascara lo que había oculto bajo ella.

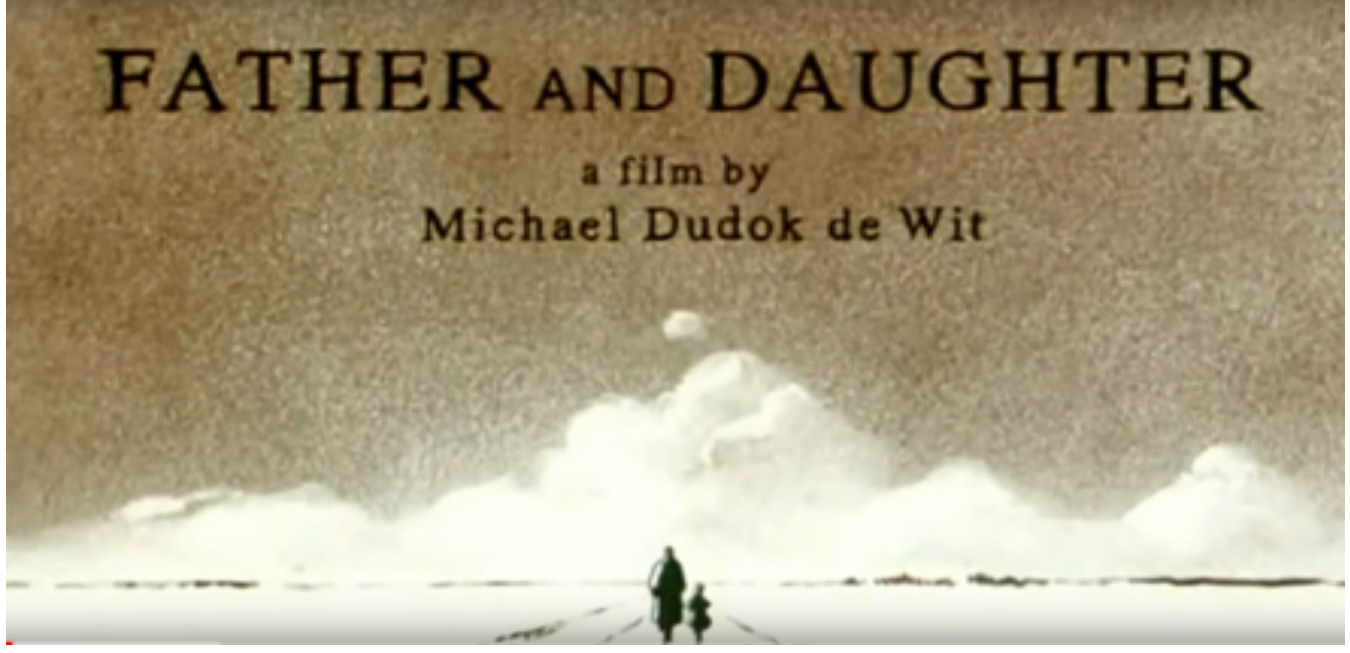

Michael Dudok de Wit (2000). Father and Daughter. Imagen recuperada de internet el 19 de noviembre de 2018. https://www.youtube.com/watch?v=wTIkvWWC23A
"Bajo el agua", como título, es primero una insinuación de lo oculto, de lo indecible, de lo que se mira de soslayo, lo que se sabe que está ahí, pero sin saber que está ahí. Su desarrollo dispara múltiples analogías que muestran como la Historia (en mayúscula) contiene las múltiples historias (en minúsculas) que la tejen en conjunto. Hay en ella algo que Morin (2006), Ilama principio hologramático, el cual refiere a la idea de que la parte contiene al todo sin fisuras ni costuras, de ahí que "Bajo el agua" dé cuen- 


\section{RESEÑA}

ta de que lo humano contiene la humanidad de la humanidad, la narración contiene la humanidad del narrador que contiene la humanidad de narradores, sea entonces como memoria instituida o como memoria recreada, por instituir (Castoriadis, 1998). Es un imaginario, que da cuenta de las conductas, de las regularidades, de las emociones y de los afectos contenidos en ellas, aquello que las condiciona como condición humana.

Michael Dudok de Wit (2000). Father and Daughter. Imagen recuperada de internet el 19 de noviembre de 2018. https://www. youtube.com/watch?v=wTIkvwwC23A

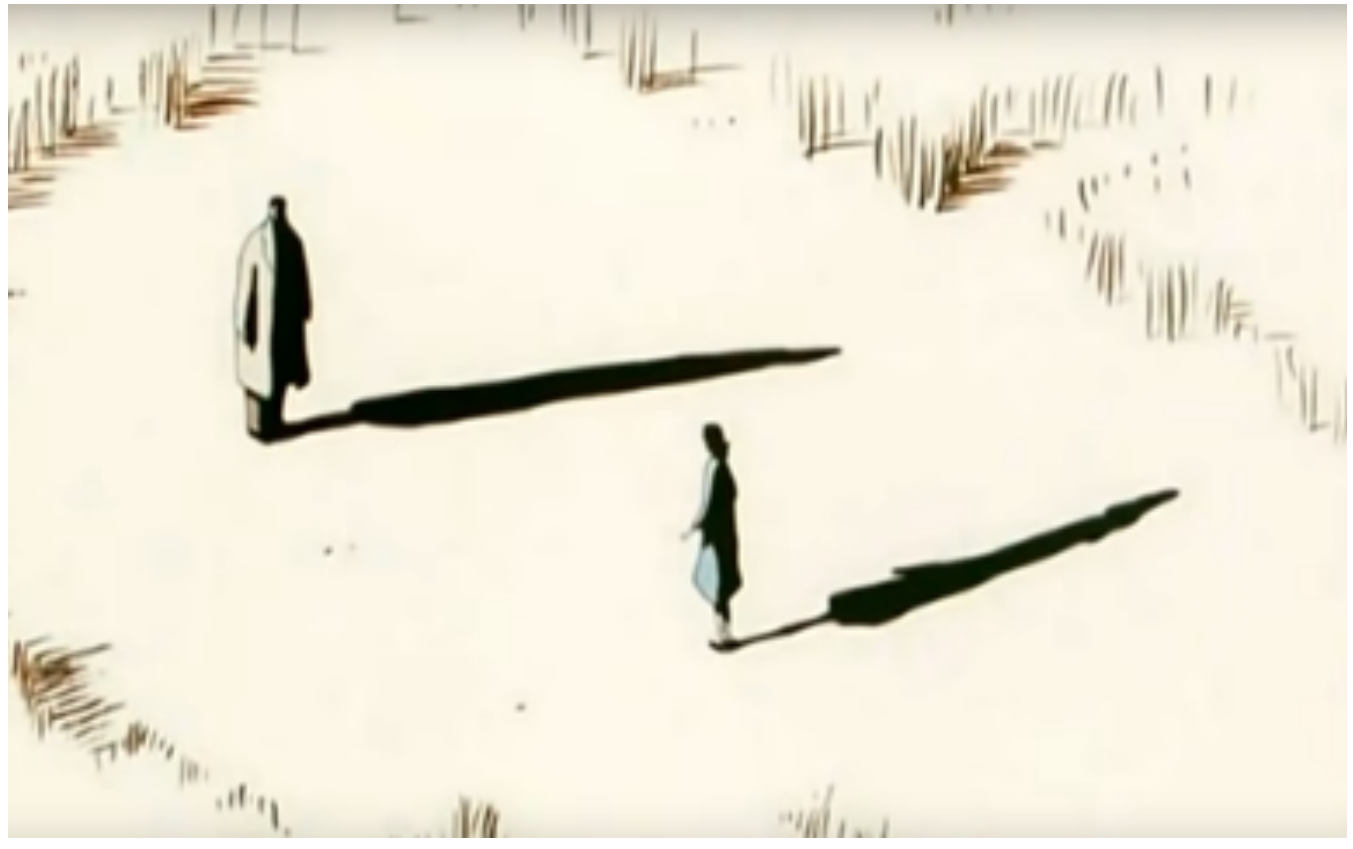

"Bajo el agua" es una historia que narra su historia a través de otras historias conectadas. Siguiendo a Luhmann (2005), podemos decir que son observaciones de diferente orden: alguien observa algo (el algo puede ser autorreferencial), alguien elabora una

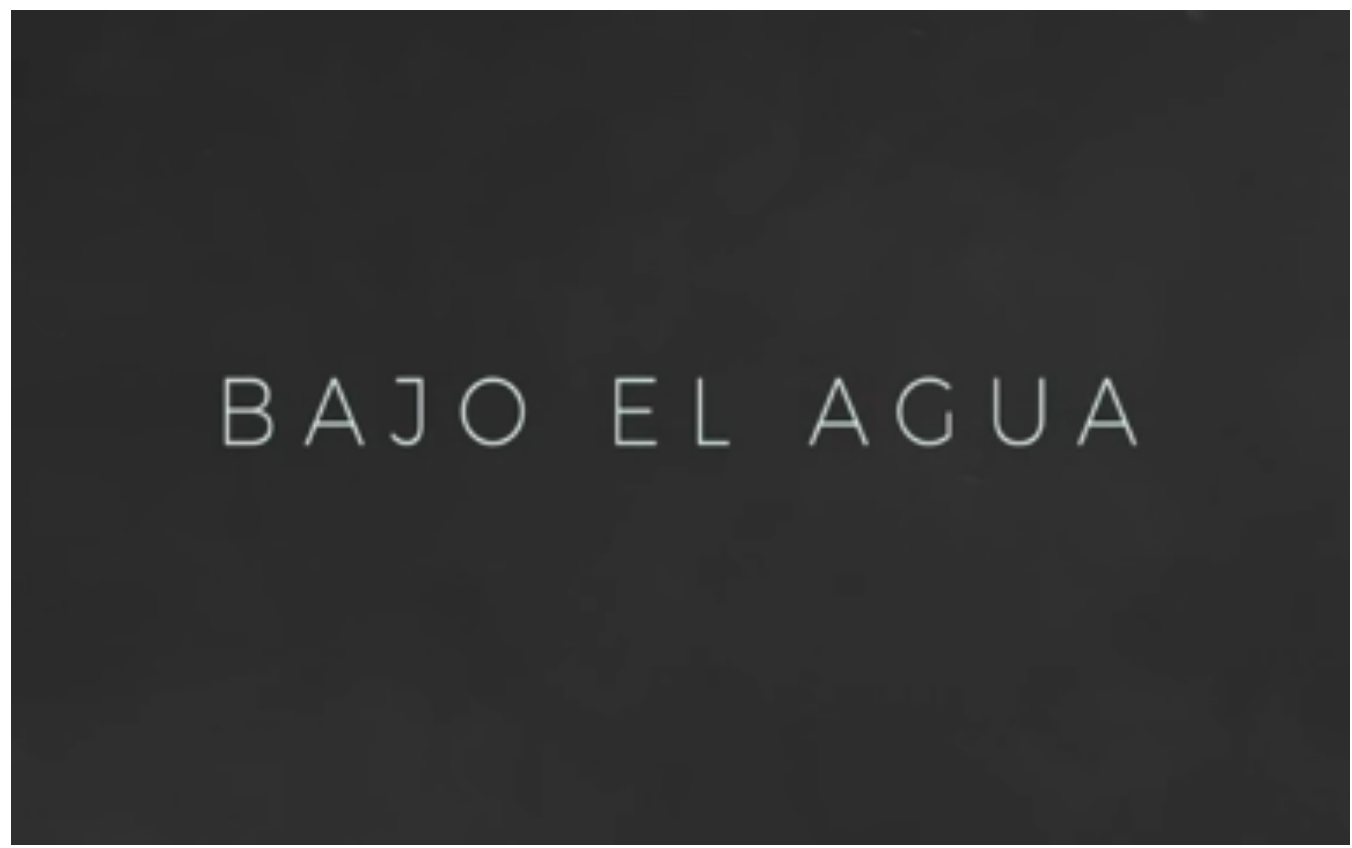




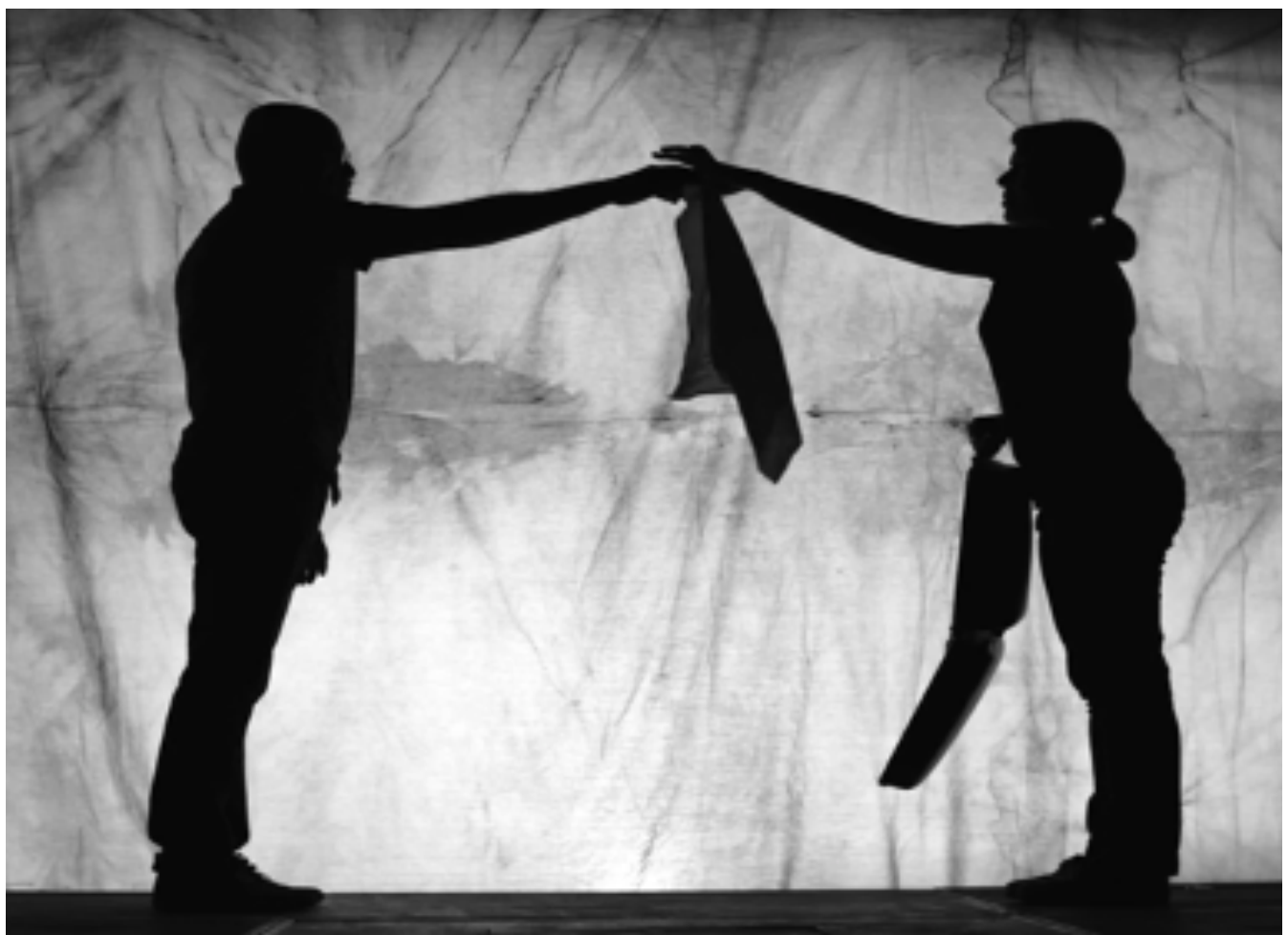

Fernanda Galindo. Bajo el agua. Imagen recuperada de internet el 21 de noviembre de 2018 https://vimeo.com/261950883

observación sobre la observación, alguien observa la observación de la observación y elabora una observación. Una historia contiene otras historias contenidas en otras historias que la contienen. Las analogías hacen su aparición como si la historia personal contara la historia de la humanidad. Sin embargo, como señala Maturana (1998), lo dicho siempre es dicho por alguien. Se trata de "escribir para explicar el silencio" (Fernanda Galindo), hacer hablar al silencio, pese a su resistencia.

El comienzo de "Bajo el agua" es un universo cerrado, como si de una historia de la Edad Media se tratara. En la Edad Media, la cruz era un código moral y religioso de observancia estricta: el palo vertical en su parte superior representa el cielo; en la inferior el infierno, el palo horizontal, a su izquierda, representa la creación; a su derecha el día del juicio final. Si unimos los vértices formamos un círculo que parece decir, si desde el principio y hasta el día del juicio final observas buena conducta irás al cielo; si no al infierno (Buber, 1967). No hay más opciones. El mundo es "encantadoramente" comprensible y cerrado, estable y seguro. Aquí no existen los "colapsos universales [ni] personales" (Fernanda Galindo), es un mundo heterónomo, dirigido y contemplado por alguna gracia o fuerza inhumana.

En su desarrollo, el universo cerrado de "Bajo el agua" se quiebra, sigo a Koyré (1999), aparece una historia moderna y con ella, el mundo se desencanta, es autónomo. Operaciones cognitivas desatan sensaciones afectivas furiosas que trastocan todos los valores y los modos de ser, el mundo se escinde, se vuelca sobre el sujeto, volviéndolo el protagonista de su confección, de su mundo por contar. El mundo ya no es más el centro del universo es solo algo minúsculo en la inmensidad del universo como lo habría sentido Pascal al mirar lo infinitamente grande del cosmos en comparación con lo infinitamente pequeño del ser humano. La narradora debe ahora construir su mundo. 


\section{RESEÑA}

El dictum nietzscheano hace su aparición, cito de memoria: Dios ha muerto, lo hemos matado, y con las manos ensangrentadas y con la sangre aún caliente en nuestras manos debemos construir la historia por venir. La historia que se cuenta en "Bajo el agua" se cierra, se insinúa la vuelta al origen, no aquella que conduce al tiempo de los griegos, donde el origen siempre fue mejor; es, en cambio, la vuelta del viaje sea como experiencia (ex -peri- fuera del peligro), de haber sobrevivido a la "muerte", lo que permite volver y contar la experiencia de vida ganada.

"Bajo el agua" cuenta la historia de la experiencia humana, cuyas imágenes como índices indican que no sólo es la historia de un narrador desdibujado en el presente, sino la construcción humana, la temporalidad de un recuerdo tejido en el conjunto de las temporalidades de los recuerdos que la hacen posible.

\section{Bibliografía}

Buber, M. (1967). ¿Qué es el hombre? (E. Imaz, Trad. 6a ed.). México: Fondo de Cultura Económica.

Castoriadis, C. (1998). Hecho y por hacer. Pensar la imaginación. Encrucijadas del laberinto V (L. Lambert y F. Urribarri, Trads. 1era ed.). Buenos Aires: Universidad de Buenos Aires-Eudeba.

Dudok de Wit, M. (Writer). (2000). Father And Daughter. In C. Jennings \& W. Thijssen (Producer). Dutch-British: CinéTé and Cloudrunner LTD.

Galindo, F. (Writer). (2017). Bajo el agua. In J. Hernández \& AEC (Producer). México: Unoenlouno.

Koyré, A. (1999). Del universo cerrado al universo infinito (C. Solís, Trad. 4a ed.). Madrid: Siglo XXI de España Editores.

Luhmann, N. (2005). El arte de la sociedad (J. Torres, B. Erker, S. Pappe, y L. Segura, Trads. 1era ed.). México: Herder-UIA.

Maturana, H. (1998). El árbol del conocimiento. Chile: Dolmen.

Morin, E. (2006). El método 4. Las ideas. Su hábitat, su vida, sus costumbres y su organización (A. Sánchez, Trans. 4ta ed. Vol. IV). Madrid: Cátedra. 